\title{
Ezetimibe reduces cholesterol content and NF-kappaB activation in liver but not in intestinal tissue in guinea pigs
}

\author{
Peter Fraunberger ${ }^{1,4^{*}}$, Elisabeth Gröne ${ }^{2}$, Hermann-Josef Gröne ${ }^{2}$, Heinz Drexel ${ }^{3}$ and Autar K. Walli ${ }^{4}$
}

\begin{abstract}
Background: Statins (HMG CoA reductase inhibitors), in addition to reducing circulating cholesterol and incidence of coronary heart disease, also have pleiotropic, anti-inflammatory effects. Patients with chronic liver diseases, non-alcoholic fatty liver disease (NAFLD) or hepatitis $C$ are often excluded from statin therapy because of adverse effects in a small cohort of patients despite increased cardiovascular risk cholesterol. Ezetimibe, which inhibits cholesterol absorption by inhibition of Niemann-Pick C1 like 1 (NPC1L1) protein in the brush border of intestinal cells, has been suggested as a new therapeutic option in these patients.

Methods: Effects of ezetimibe on lipoprotein metabolism, hepatic and intestinal lipid content in guinea pigs, an animal model with a lipoprotein profile and pattern similar to humans were investigated. In order to investigate a possible effect of ezetimibe on cholesterol induced inflammation NF-kappaB activation as an indicator for inflammatory processes in liver and gut tissue was measured.

Results: Lipid enriched diet led to accumulation of lipids in hepatic tissue which caused strong hepatic NF-kappaB activation. Ezetimibe reduced lipid diet induced increase of circulating cholesterol by about $77 \%$ and prevent hepatic NF-kappaB activation almost completely. In contrast in intestinal cells Ezetimibe, though lowering diet induced cholesterol accumulation, increased triglyceride content and subsequent NF-kappaB activation.

Conclusion: In summary these data show, that ezetimibe effectively reduced diet induced circulating cholesterol levels, hepatic lipid accumulation and inflammatory response in our guinea pig model. However this drug elicited a local inflammatory response in intestinal tissue. Whether these diverse effects of ezetimibe on inflammatory parameters such as NF-kappaB have clinical relevance remains to be determined.
\end{abstract}

Keywords: Inflammation, Cholesterol, Ezetimibe, Guinea pigs, Liver, Intestine

\section{Background}

Although statins (HMG CoA reductase inhibitors) very rarely cause clinically significant liver injury, asymptomatic elevation in aminotransferases is common [1]. Therefore patients with chronic liver diseases, non-alcoholic fatty liver disease (NAFLD) or hepatitis C are often excluded from statin therapy despite increased cardiovascular risk [2]. To achieve a relevant reduction of cholesterol in plasma, cholesterol absorption inhibitor ezetimibe [1-(4-fluorophenyl)-(3R)-[3-(4-fluorophenyl)-(3S)-

\footnotetext{
* Correspondence: pfraunberger@mzl.at

${ }^{1}$ Medical Central Laboratories, Carinagasse 41, A-6800 Feldkirch, Austria ${ }^{4}$ Institute of Laboratory Medicine, Ludwig-Maximilians-University, Munich, Germany

Full list of author information is available at the end of the article
}

hydroxypropyl]-(4S)-(4-hydroxypropyl)-2-azetidinone] has been suggested as an additional therapy to low dose statins. Combination of low dose statins $(10 \mathrm{mg} /$ day $)$ with administration has even been shown to be more effective than statin monotherapy $[3,4]$. Recent data show that ezetimibe also reduces insulin resistance, dyslipidaemia and hepatic fat accumulation in patients with NAFLD [5-7]. Therefore this drug has been suggested as a new therapeutic option in these patients. Hepatic fat accumulation is an essential feature of NAFLD and may stem from dietary fat, from adipocytes via lipolysis and from de novo lipogenesis. Although fatty liver is thought to be benign, accumulation of lipids can lead to lipotoxicity resulting in inflammation, probably due to oxidative processes $[8,9]$. 
Specifically lipotoxicity can induce cell proliferation, NFkappaB activation, release of proinflammatory cytokines and subsequent cell death. Although the extent of inflammation varies considerably in steatohepatitis, in some cases it may lead to hepatic injury, cirrhosis and hepatocellular carcinoma [10].

Ezetimibe inhibits cholesterol absorption as well as its reuptake via the enterohepatic cycle in the mucosa of the small intestine without affecting the absorption of triglycerides or fat-soluble vitamins [11]. The molecular target of ezetimibe is the Niemann-Pick C1 like 1 (NPC1L1) protein in the brush border of intestinal cells although other proteins may be also involved [12]. NPC1L1 protein is necessary to transport unesterified cholesterol from the intestine to the endoplasmatic reticulum, where it is esterified and assembled into chylomicrons particles. Inhibition of NPC1L1 protein thereby decreases the amount of cholesterol delivered by chylomicrons to the liver [13]. However NPC1L1 receptor is also highly expressed in hepatocytes and is thought to play a role in regulating biliary cholesterol concentration [14]. This may explain recent observations, that inhibition of NPC1L1 by ezetimibe modulates hepatic and metabolic disorders in rodents [15-17]. However value of studies in animal models such as mice and rat is limited because LDL is not the main cholesterol transporting lipoprotein and hepatic lipid metabolism may differ from humans. Ezetimibe reduces LDL by about $18-20 \%$ which may be effective reduction in borderline patients, but unfortunately no detailed studies about clinical safety of this drug are available to date [18].

Statins, which effectively reduce circulating cholesterol, have been shown to exhibit a wide variety of immunomodulatory effects independent of their lipid lowering effects [19]. In contrast, pleiotropic effects of ezetimibe are still under debate. Whereas some studies indicate an antiinflammatory effect $[20,21]$, other studies found no effects on inflammation [22, 23].

Accordingly this study was designed to determine the effects of ezetimibe on lipid metabolism, tissue lipid content and NF-kappaB activation in hepatic and intestinal tissue of guinea pigs. This animal model was chosen because its lipoprotein profile, response to statins, hepatic HMG-CoA reductase activity, and rates of hepatic cholesterol synthesis are similar to humans [24].

\section{Methods}

\section{Biochemicals}

All chemicals and biochemicals were obtained from Sigma Chemie GmbH (München, FRG), E. Merck GmbH (Darmstadt, FRG) or Roche (Mannheim, FRG). Bovine serum albumin was obtained from Behring (Marburg, FRG). Fetal calf serum was from Gibco Europe Ltd. (Eggstein, FRG). ${ }^{125}$ I-sodium iodide, DL $\left[2-{ }^{3} \mathrm{H}\right]$-mevalonic acid and ${ }^{14} \mathrm{C}$ - cholesteryloleate were purchased from Amersham Buchler GmbH \& Co. KG (Braunschweig, FRG), 3-hydroxyl[ $\left.3{ }^{14} \mathrm{C}\right]-$ methylglutaryl CoA (HMG-CoA) from Du Pont, NEN Products (Boston, MA, USA). Ezetimibe [1-(4-fluorophenyl)-(3R)-[3-(4-fluorophenyl)-(3S)-hydroxypropyl]-

(4S)-(4-hydroxypropyl)-2-azetidinone] was provided by Merck, Sharp \& Dome Resarch Laboratories (West Point, PA, USA).

\section{Animal procedures}

Male Dunkin-Heartley guinea pigs (300-400 g body weight) obtained from Charles River, Kisslegg, Germany, were maintained in a light-cycle room (dark from 7:00 a.m. to 7:00 p.m., light from 7:00 p.m. to 7:00 a.m.) and had free access to food and water ad libitum. Diets were prepared as previously described by Conde et al. [25]. All diets were prepared and pelleted by Fa. ssniff $\mathrm{G}^{\circ}$ (Germany). Composition of chow diet was as follows: $21 \%$ protein, $3 \%$ fat, $14 \%$ fiber, $8,3 \%$ essential minerals, 0,007\% vitamin $\mathrm{E}$ and $0.015 \%$ vitamin C. Cholesterol diet contained $0,2 \%$ cholesterol and $15 \%$ fat consisting olive, palm kernel and safflower oil (1:2:1,8). Ezetimibe diets were prepared as described above but contained in addition $0.005 \%$ ezetimibe.

After 1 week of adaptation guinea pigs were maintained on the indicated diets for further 2 weeks. Animal groups were as follow: Chow diet $(n=12)$, Cholesterol diet $(n=12)$, Chow diet plus Ezetimibe $(n=4)$, Cholesterol diet plus Ezetimibe $(n=8)$. All experiments were carried out between 8 and $10 \mathrm{am}$.

\section{Blood and tissue samples}

Blood was obtained by aortic puncture and collected in tubes containing EDTA. These tubes were centrifuged at $5,000 \mathrm{~g}$ for $15 \mathrm{~min}$ at $4{ }^{\circ} \mathrm{C}$. Plasma was separated and stored at $4{ }^{\circ} \mathrm{C}$. Liver tissue was frozen by Wollenberger technique in liquid $\mathrm{N}_{2}$ [26] and stored at $-196{ }^{\circ} \mathrm{C}$ for biochemical analysis. Gut tissue was washed twice with saline. Liver and gut tissue were frozen immediately in liquid nitrogen $\left(-180^{\circ} \mathrm{C}\right)$ for immunohistological studies.

\section{Clinical chemistry measures}

Cholesterol and triglyceride plasma levels $[\mathrm{mg} / \mathrm{dl}]$ as well as aspartate aminotransferase (AST), alanine transaminase (ALT) and gamma-glutamyl transpeptidase (gGT) activities in plasma [U/l] were measured with Roche automated system (Integra 800, Roche diagnostics).

\section{Electrophoretic mobility shift assay (EMSA)}

Nuclear extracts from gut and liver tissue: Nuclear extracts were prepared as described by Fukuma et al. [27]. Briefly, tissue was homogenized in homogenizing buffer (10 mM HEPES-buffer $\mathrm{pH}$ 7.6, containing $0.1 \mathrm{mM}$ EDTA, $15 \mathrm{mM} \mathrm{KCl,} 2 \mathrm{mM} \mathrm{MgCl}$, $1 \mathrm{mM}$ DTT, $1 \mathrm{mM}$ 
phenylmethylsulfonyl fluoride (PMSF) and 1\% protease inhibitor cocktail). This homogenate was centrifuged at $850 \mathrm{xg}$ and supernatant was discarded. Cell pellet was incubated in homogenizing buffer containing $0.2 \%$ Igepal (Sigma, Germany) on ice for $10 \mathrm{~min}$ and centrifuged. After discarding the supernatant pellet was rinsed in homogenizing buffer containing 0.25 sucrose, centrifuged for $5 \mathrm{~min}$ at $850 \times \mathrm{g}$ and supernatant was discarded. Finally pellet was suspended in nuclear extraction buffer $(50 \mathrm{mM}$ HEPES, pH 7.9, containing $0.1 \mathrm{mM}$ EDTA, $0.4 \mathrm{mM} \mathrm{KCl}$, $10 \%$ glycerol, $1 \mathrm{mM}$ DTT, $0.5 \mathrm{mM}$ PMSF and 1\% protease inhibitor cocktail) and was shaken for $30 \mathrm{~min}$ at $4{ }^{\circ} \mathrm{C}$, centrifuged at $12,000 \times \mathrm{g}$ for $5 \mathrm{~min}$. Supernatant (nuclear extract) was kept frozen at $-80{ }^{\circ} \mathrm{C}$.

DNA binding assay: NF-kappaB consensus oligonucleotides GPNFKB-01 L: 5'-AGT-TGA-GGG-GAC-TTTCCC-AGG-C-3' and GPNFKB-02 k: 5' -GCC-TGG-GAAAGT-CCC-CTC-3' (Eurogentec, Belgien) were annealed and labeled with [alpha- ${ }^{32} \mathrm{P}$ ]dATP (Amersham Germany) in the presence of deoxynucleoside triphosphates by primer extension with the Klenow fragment of DNA polymerase I (Roche, Mannheim, Germany). Nuclear proteins were incubated with ${ }^{32} \mathrm{P}$ labeled oligonucleotide in binding buffer $(10 \mathrm{mM}$ Tris-buffer $\mathrm{pH} 7.5$, containing $50 \mathrm{mM}$ $\mathrm{NaCl}, 5 \mathrm{mM} \mathrm{MgCl} 2,1 \mathrm{mM}$ EDTA, $10 \%$ glycerol, $5 \mu \mathrm{g}$ bovine serum albumin, $0.2 \%$ Nonidet P- $40,4 \mu \mathrm{g}$ poly-(dI$\mathrm{dC}$ ) und $1 \mathrm{mM}$ DTT) for 15-30 min. DNA bound NFkappaB was separated by electrophoresis on $5 \%$ acryl/bisacrylamid gel in $0.25 \times$ Tris borate EDTA buffer $\left(4{ }^{\circ} \mathrm{C}\right)$. Each lane contained $5 \mu \mathrm{g}$ nuclear protein and 60,000 CPM. Gels were dried, exposed to storage phosphor screens, read in a phosphorimager (Storm, Molecular Dynamics, USA) and quantified using ImageQuant software (ImageQuant ${ }^{\circ}$, Molecular Dynamics, USA).

\section{HMG CoA reductase activity in liver microsomes and LDL binding to hepatic membranes}

Isolation of liver microsomes and incubation of microsomes with $\left[{ }^{14} \mathrm{C}\right]$-HMG-CoA was performed as described by Walli and Seidel [28], with the exception that $\left[{ }^{14} \mathrm{C}\right]$-mevalonolactone was separated from ${ }^{14} \mathrm{C}$ HMG-CoA by column chromatography. Lactonised incubates $(0.05 \mathrm{ml})$ were applied to a $0.5 \times 5 \mathrm{~cm}$ column containing 100-200 mesh Bio-Rex, chloride form (Bio Rad, Munich, FRG) which was equilibrated with distilled water. $\left[{ }^{14} \mathrm{C}\right]$-mevalonolactone was eluted with $2 \mathrm{ml}$ of distilled water directly into scintillation vials. After addition of $10 \mathrm{ml}$ Ultima Gold scintillation fluid (Packard Instr., Zürich, Switzerland) radioactivity was measured in a scintillation counter. Binding of LDL to hepatic membranes was assayed according to Kovanan et al. [29]. Briefly membranes were isolated from homogenized liver tissue by ultracentrifugation. For binding assay ${ }^{125}$ I labeled apo-E rich human VLDL was used as a ligand. Maximal binding affinity was calculated by scatchard plot analysis.

\section{Lipid content in liver and gut}

Tissue lipids were measured according to Carr et al. [30]. ${ }^{14} \mathrm{C}$-cholesteryloleate was added as an internal standard.

\section{Histology}

Liver and intestine tissue were removed from animals under deep anesthesia, quickly blotted free of blood, weighed, and processed for histology, immunohistology, and gel shift analysis. Tissue samples, $3-4 \mu \mathrm{m}$ in thickness, were prepared using cryostat technology (CM1900, Leica), mounted on poly-L-lysine coated slides, dried at room temperature for $1 \mathrm{~h}$ and stained with oil red for fat staining. For immunohistology samples were cut into $1-\mathrm{mm}$ thick slices, immersed in $4 \%$ formaldehyde and then embedded in paraffin. In addition tissue slices were snap frozen in liquid nitrogen and stored at $-80{ }^{\circ} \mathrm{C}$ for further analysis.

\section{Immunohistology}

Immunohistochemical staining was done on sections of paraffin-embedded tissue samples. Primary antibody mouse anti-human NF-kappaB p50 (Santa Cruz Biotechnology, USA) was diluted 1:200 with PBS containing 0.05\% Tween and $1 \%$ BSA. Biotinylated rabbit anti-mouse immunoglobulins (DAKO, Germany), diluted 1:200 in PBS-BSA served as a secondary antibody. After $30 \mathrm{~min}$ incubation, slides were washed twice in PBS-Tween for $10 \mathrm{~min}$ each. This was followed by incubation with streptavidin-horse reddish peroxidase (HRP) (DAKO, Germany) diluted 1:200 for $20 \mathrm{~min}$. Substrate 3-amino-9-ethyl -carbazole (ACE) (0.01\%) containing $0.006 \% \mathrm{H}_{2} \mathrm{O}_{2}$ was added shortly before use for colour development. Sections were counterstained with Harris modified Hematoxylin 1:4 (Sigma, Germany) for $30 \mathrm{~s}$. Slides were examined under light microscope and film EPY 64 T (Kodak, Germany) was used for photographs.

In order to establish, whether gel shift assay as well as immunohistology was suitable in the present model, guinea pigs were treated intraperitoneally with LPS ( $2 \mathrm{mg} / \mathrm{kg}$ body weight) to induce endotoxinemia and sepsis. Figure 1 shows gelshift analysis of NF-kappaB activation in liver and gut tissue by EMSA (A) and immunohistology (B). As expected, LPS activated NF-kappaB in both, liver and intestine tissue.

\section{Statistics}

All data are given as means \pm standard deviation (SD) and compared using the Wilcoxon, Mann-Whitney rank sum test for non-parametric data and $\mathrm{t}$-test for parametric data. $P$ values $<0.05$ were considered as statistically significant. 
a

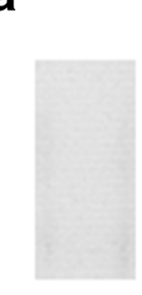

b

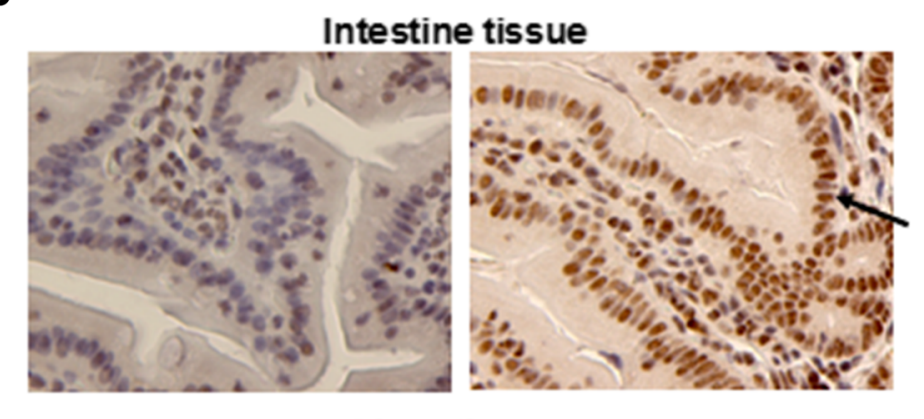

Liver tissue

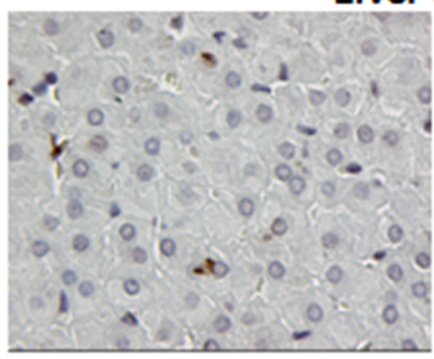

- LPS

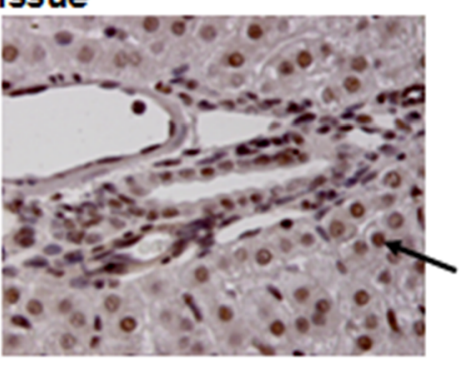

Fig. 1 Representative gelshift assays of NF-kappaB in nuclear extracts from (a) and immuncytochemical detection of NF-kappB (b) in liver and intestine to establish suitability of gel shift assay and immunohistology in this model. Animals were treated with saline or LPS (2 mg/kg body weight) and killed after the indicated time to obtain liver and intestine tissue. Arrow denotes nuclear NF-kappaB staining

\section{Results}

\section{Effect of ezetimibe on lipoprotein metabolism}

Chow diet together with ezetimibe decreased circulating levels of cholesterol in guinea pigs by $42 \%$ whereas triglyceride levels remained unchanged. Cholesterol diet increased these levels by ten and three fold, respectively compared to chow diet. Cholesterol diet in combination with ezetimibe decreased circulating cholesterol by about $77 \%$ compared to cholesterol diet alone without altering triglyceride levels (Table 1 ).

Ezetimibe diet increased HMG-CoA reductase activity by about 2,6 fold whereas cholesterol diet inhibited enzyme activity almost completely (Table 2). However cholesterol enriched diet together with ezetimibe prevent this effect. Maximal binding of apo-E rich VLDL by isolated hepatic membranes was unaffected by ezetimibe. Cholesterol enriched diet increased hepatic membrane binding by about $30 \%$. Cholesterol diet in combination with ezetimibe did not significantly affect maximal binding capacity of apo-E rich ligand on hepatic membranes. In contrast a minimal reduction of binding affinity as reflected by $\mathrm{Km}$ in animals on chow or cholesterol enriched diet was noted after ezetimibe treatment.

Table 1 Plasma levels of cholesterol and triglycerides in guinea pigs on chow or cholesterol diet with or without Ezetimibe

\begin{tabular}{lllllllc}
\hline Diet & $\mathrm{n}$ & \multicolumn{3}{c}{ Cholesterol [mg/dl] } & \multicolumn{2}{l}{ Triglycerides [mg/dl] } \\
\hline Chow & 11 & 36 & \pm & 18 & 114 & \pm & 60 \\
Ezetimibe & 4 & 21 & \pm & $5^{\mathrm{a}}$ & 72 & \pm & 5 \\
Cholesterol & 12 & 303 & \pm & $91^{\mathrm{b}}$ & 302 & \pm & $168^{\mathrm{b}}$ \\
Cholesterol + Ezetimibe & 7 & 69 & \pm & $28^{\mathrm{c}}$ & 281 & \pm & $105^{\mathrm{b}}$ \\
\hline
\end{tabular}

${ }^{a}$ significantly different from Chow-diet, ${ }^{b}$ significantly different from Chow and Ezetimibe diet, 's significantly different from Ezetimibe and Cholesterol diet 
Table 2 HMG-CoA reductase activity in liver microsomes, Vmax and Km in liver membranes in guinea pigs on chow or cholesterol diet with or without Ezetimibe

\begin{tabular}{|c|c|c|c|c|}
\hline Diet & $n$ & HMG-CoA reductase [pmol/mg Protein/min] & Vmax [ $\mathrm{\mu g} / \mathrm{mg}$ Protein] & $\mathrm{Km}[\mu \mathrm{g} / \mathrm{ml}$ Medium] \\
\hline Chow & 11 & $22,2 \pm 7,2$ & $1,22 \pm 0,21$ & $23,6 \pm 4,05$ \\
\hline Ezetimibe & 4 & $57,0 \pm 28,7^{a}$ & $1,39 \pm 0,11$ & $21,56 \pm 1,8$ \\
\hline Cholesterol & 12 & $1,2 \pm 0,5^{b}$ & $1,8 \pm 0,45$ & $35,50 \pm 7,5$ \\
\hline Cholesterol + Ezetimibe & 7 & $25,4 \pm 7,0^{c}$ & $1,76 \pm 0,35$ & $32,24 \pm 7,0$ \\
\hline
\end{tabular}

${ }^{a}$ significantly different from Chow-diet, ${ }^{b}$ significantly different from Chow and Ezetimibe diet, ${ }^{c}$ significantly different from Ezetimibe and Cholesterol diet

Effect of ezetimibe on liver enzyme activities in plasma Cholesterol feeding induced a significant increase of markers of liver disease such as aspartate aminotransferase (AST), alanine transaminase (ALT) and gamma-glutamyl transpeptidase (gGT). In particular ALT, which is recognized as a biochemical marker for fatty liver disease, was increased about 2 fold. All three parameters returned to normal circulating values on cholesterol enriched diet containing Ezetimibe. Ezetimibe alone had no effect on these markers (Table 3).

\section{Effect of ezetimibe on lipid content of liver and intestinal tissue \\ Liver}

Ezetimibe did not change hepatic content of cholesterol, triglycerides or phospholipids in animals on chow diet. In animals fed with cholesterol enriched diet hepatic cholesterol, triglycerides and phospholipids increased by 5.7, 8.4 and 1.4 fold, respectively. This increase in cholesterol and phospholipid content was almost completely prevented by addition of Ezetimibe. However triglyceride content in liver tissue was still 2 fold higher when compared to animals on chow diet (Table 4).

\section{Intestine}

In animals maintained on chow diet containing ezetimibe no significant changes in cholesterol and phospholipids content but a 2-fold increase in triglycerides was observed. Cholesterol diet increased cholesterol, triglyceride and phospholipid content by 1.54, 3.9 and 1.3 fold, respectively. Cholesterol diet supplemented with ezetimibe reduced cholesterol content by $24 \%$ but increased triglyceride

Table 3 Circulating levels of AST, ALT and y-GT in guinea pigs on chow or cholesterol diet with or without Ezetimibe

\begin{tabular}{llclc}
\hline Diet & $\mathrm{n}$ & $\mathrm{AST}[\mathrm{U} / \mathrm{l}]$ & $\mathrm{ALT}[\mathrm{U} / \mathrm{I}]$ & $\mathrm{gGT}[\mathrm{U} / \mathrm{l}]$ \\
\hline Chow & 12 & $56 \pm 13$ & $40 \pm 8$ & $7 \pm 2$ \\
Ezetimibe & 4 & $64 \pm 35$ & $41 \pm 17$ & $5 \pm 1$ \\
Cholesterol & 12 & $143 \pm 47^{\mathrm{a}}$ & $69 \pm 28^{\mathrm{a}}$ & $30 \pm 27^{\mathrm{a}}$ \\
Cholesterol + Ezetimibe & 8 & $71 \pm 16$ & $47 \pm 6$ & $10 \pm 3$ \\
\hline
\end{tabular}

${ }^{a}$ significantly different from Chow diet and Ezetimibe diet content by about $45 \%$ fold. Phospholipid content remained unchanged by this diet (Table 5).

Next we stained frozen sections of hepatic and intestinal tissue for neutral lipids (Fig. 2). Cholesterol enriched diet led to increased neutral lipid staining in both hepatic and intestinal tissue. Animals maintained on cholesterol enriched diet containing ezetimibe showed decreased neutral lipid staining only in hepatic tissue whereas in intestinal tissue no decrease of neutral lipids was noted.

\section{Effect of ezetimibe on NF-kappaB activation Liver}

Gel shift assays in nuclear extracts from liver tissue showed about 4 fold activation of NF-kappaB by a cholesterol enriched diet $(48,337 \pm 14,558$ vs. $213,650 \pm 79,521$ arbitrary units, $p<0.05)$. Addition of ezetimibe to cholesterol enriched diet almost completely abolished this NF-kappaB activation $(213,650 \pm 79,521$ vs. $58,555 \pm 25,843$ arbitrary units, $p<0.05$ ). Ezetimibe without cholesterol diet had no effect on hepatic NF-kappaB activation (Fig. 3a).

\section{Intestine}

Ezetimibe alone did not alter NF-kappaB activation (Fig 3b). However in animals fed on cholesterol diet, addition of ezetimibe induced approximately 2 fold increase of NF-kappaB activation.

This ezetimibe induced NF-kappaB activation was confirmed by immunohistological studies (Fig. 4). In animals on cholesterol diet an increased staining of NFkappaB in nuclei of liver cells could be detected, whereas addition of ezetimibe to cholesterol diet prevented this effect. In animals fed with ezetimibe alone, no nuclear staining of NF-kappaB was visible. In intestine tissue neither cholesterol nor ezetimibe alone induced NFkappaB activation. However when ezetimibe was added to cholesterol diet a strong increase of NF-kappaB staining was noted in nuclei of intestinal cells.

\section{Discussion}

Ezetimibe is a new lipid-lowering agent that inhibits intestinal absorption of dietary and biliary cholesterol with subsequent decrease of about $10-20 \%$ in circulating 
Table 4 Lipid in content in liver in guinea pigs on chow or cholesterol diet with or without Ezetimibe

\begin{tabular}{lllll}
\hline Diet & $\mathrm{n}$ & Cholesterol [mg/g] & Triglycerides [mg/g] & Phospholipids [mg/g] \\
\hline Chow & 10 & $1,23 \pm 0,3$ & $1,65 \pm 0,4$ & $9,56 \pm 1,7$ \\
Ezetimibe & 3 & $1,32 \pm 0,2$ & $1,59 \pm 0,1$ & $10,38 \pm 0,1$ \\
Cholesterol & 8 & $7,22 \pm 2,1^{\mathrm{a}}$ & $13,77 \pm 3,1^{\mathrm{a}}$ & $13,12 \pm 3,1^{\mathrm{a}}$ \\
Cholesterol + Ezetimibe & 7 & $1,53 \pm 0,3$ & $3,85 \pm 1,1^{\mathrm{b}}$ & $9,73 \pm 1,4$ \\
\hline
\end{tabular}

${ }^{a}$ significantly different from Chow-, Ezetimibe- and Cholesterol + Ezetimibe diet, ${ }^{b}$ significantly different from chow, Ezetimibe and cholesterol diet

cholesterol levels both in human and animal studies. However, it has not been shown, whether monotherapy with ezetimibe has any beneficial effect in CHD patients [18]. Although combination of low dose statins $(10 \mathrm{mg} /$ day) with ezetimibe administration lowers circulating LDL-cholesterol, combination of statins with niacin is superior to ezetimibe in lowering carotid intima thickness [31]. Furthermore some studies raised concerns about a higher cancer incidence in patients treated with ezetimibe plus simvastatin [32].

We therefore investigated effects of ezetimibe on guinea pigs, which are a suitable animal model because their lipoprotein profile, rates of cholesterol synthesis and dietary response is similar to humans. It has been shown, that combinations of high dietary cholesterol with increased fat content effectively increase circulating LDL cholesterol in this animal model. Furthermore cholesterol lowering drugs such as statins strongly reduce the dietary induced LDL cholesterol levels [24, 25].

In our study we found a $77 \%$ reduction of high cholesterol diet induced circulating cholesterol with Ezetimibe. Furthermore hepatic HMG-CoA reductase activity, which was strongly suppressed by cholesterol diet, returned to control level in ezetimibe treated animals which indirectly confirms the cholesterol lowering effect of the drug in this animal model. It is well established that enterocytes derive their cholesterol by absorption from the intestinal lumen, intracellular synthesis and uptake of LDL from the plasma. Under physiological conditions the amount of absorbed cholesterol by far exceeds new synthesis as well as receptor mediated uptake from the plasma. Enterocytes takes up dietary cholesterol and also cholesterol from enterohepatic recirculation. In the present study cholesterol enriched diet increased cholesterol and triglyceride content of intestine by 1,5 and 3.9 fold, respectively (see Fig. 2 and Table 4).

Ezetimibe inhibits NPC1L1 protein resulting in reduction of micellar cholesterol to the endoplasmatic reticulum which may cause alteration in lipid distribution in chylomicrons [12]. High fat diet loads the intestinal lumen with micellar triglycerides; after entry into enterocytes these are converted to triglyceride rich chylomicrons. During ezetimibe treatment chylomicron particles are cholesterol depleted. Whether their transport out of enterocytes was hampered leading to an intracellular triglyceride rise remains to be analyzed. In a rare genetic disease, chylomicrons retention disease, it has been shown, that assembly of chylomicrons and their delivery into the circulation may be responsible for their retention in intestine. These patients accumulate chylomicrons like lipid droplets containing apoB-48 resulting in a phenotype similar to the histological findings in this study.

In monkeys as well as in humans it has been shown, that treatment with ezetimibe reduce cholesterol content of chylomicrons but did not significantly reduce apo B48 concentrations or kinetics suggesting that ezetimibe reduce LDL cholesterol by decreasing delivery of cholesterol from the intestine to the liver rather than by reducing chylomicrons particle number [33, 34]. These effects may have significance in humans, who usually receive ezetimibe in combination with statins.

Various studies show that ezetimibe does not affect triglyceride absorption; only minor decreases of circulating triglyceride levels have been reported [35, 36]. In our guinea pig model we found an increased intestinal triglyceride content probably due to chylomicron retention but a decrease of circulating triglycerides of by ezetimibe (about 37\%) in animals on chow diet, which however was not statistically significant. This

Table 5 Lipid content in gut in guinea pigs on chow or cholesterol diet with or without Ezetimibe

\begin{tabular}{lllll}
\hline Diet & $\mathrm{n}$ & Cholesterol $[\mathrm{mg} / \mathrm{g}]$ & Triglycerides [mg/g] & Phospholipids [mg/g] \\
\hline Chow & 11 & $1,18 \pm 0,2$ & $1,69 \pm 0,8$ & $5,29 \pm 0,9$ \\
Ezetimibe & 3 & $0,96 \pm 0,3$ & $3,07 \pm 1,1^{\mathrm{c}}$ & $4,29 \pm 1,1$ \\
Cholesterol & 12 & $1,82 \pm 0,3^{\mathrm{a}}$ & $6,63 \pm 2,3^{\mathrm{a}}$ & $6,65 \pm 1,9$ \\
Cholesterol + Ezetimibe & 6 & $1,39 \pm 0,3^{\mathrm{d}}$ & $9,67 \pm 2,5^{\mathrm{b}}$ & $6,97 \pm 1,3$ \\
\hline
\end{tabular}

${ }^{a}$ significantly different from Chow, Ezetimibe and Cholesterol + Ezetimibe diet, ${ }^{b}$ significantly different from Chow, Ezetimibe and Cholesterol diet, ${ }^{c}$ significantly different from Chow, Cholesterol and Cholesterol + Ezetimibe diet, ${ }^{d}$ significantly different from Chow and Cholesteroldiet 


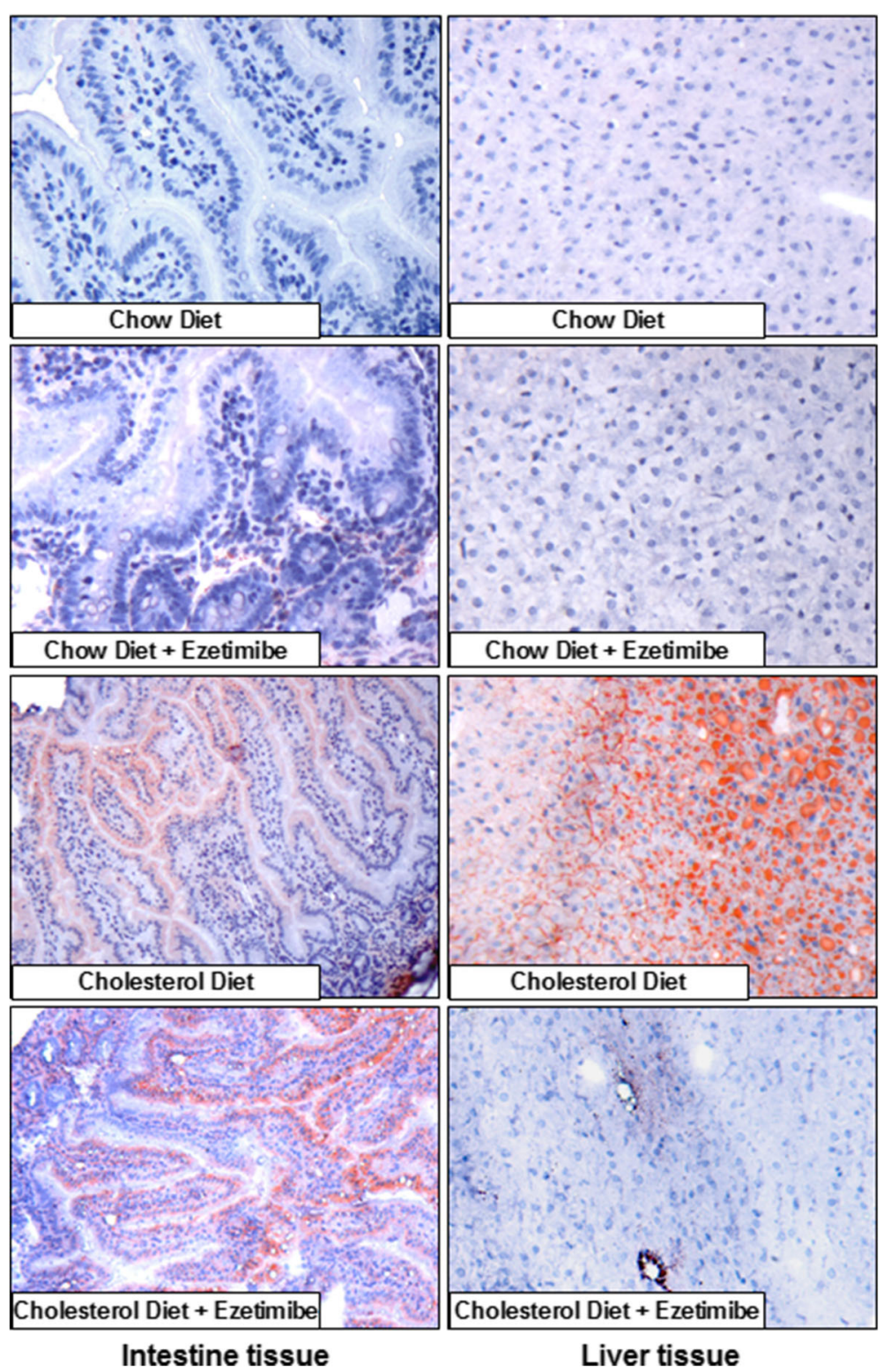

Fig. 2 Oil red staining of liver and intestine tissue of guinea pigs maintained on various diets. Animals were fed with the indicated diet for 2 weeks. Oil red staining was performed on frozen liver and intestine sections

decrease though not significant may be due to reduced chylomicrons remnant cholesterol delivery to the liver [13].

In animals on cholesterol enriched diet we found a strong decrease of circulation cholesterol by ezetimibe but statistically insignificant changes of circulating triglycerides. These effects may be due to constant influx of triglyceride rich but cholesterol depleted apoB-48 rich chylomicrons remnants to the liver which result in reduced VLDL production and subsequent reduced circulating LDL, which is the main cholesterol carrying lipoprotein in guinea pigs.
Recent reports suggest a potential benefit of ezetimibe on non-alcoholic fatty liver disease (NAFLD) by improving hepatic insulin sensitivity and decreasing lipid accumulation and hepatic inflammation [37]. Guinea pigs maintained on fat enriched diet mimic human NAFLD. Ezetimibe ameliorates the neutral fat accumulation in these animals as well as markers of liver damage. Cellular lipid accumulation may cause lipotoxicity leading to inflammatory processes and activation of NF-kappaB and subsequent release of inflammatory cytokines such as TNF-a, TGF-b, IL-6 and IL-8 [8, 38-41]. Consistent with this hypothesis activation of NF-kappaB was observed 
a
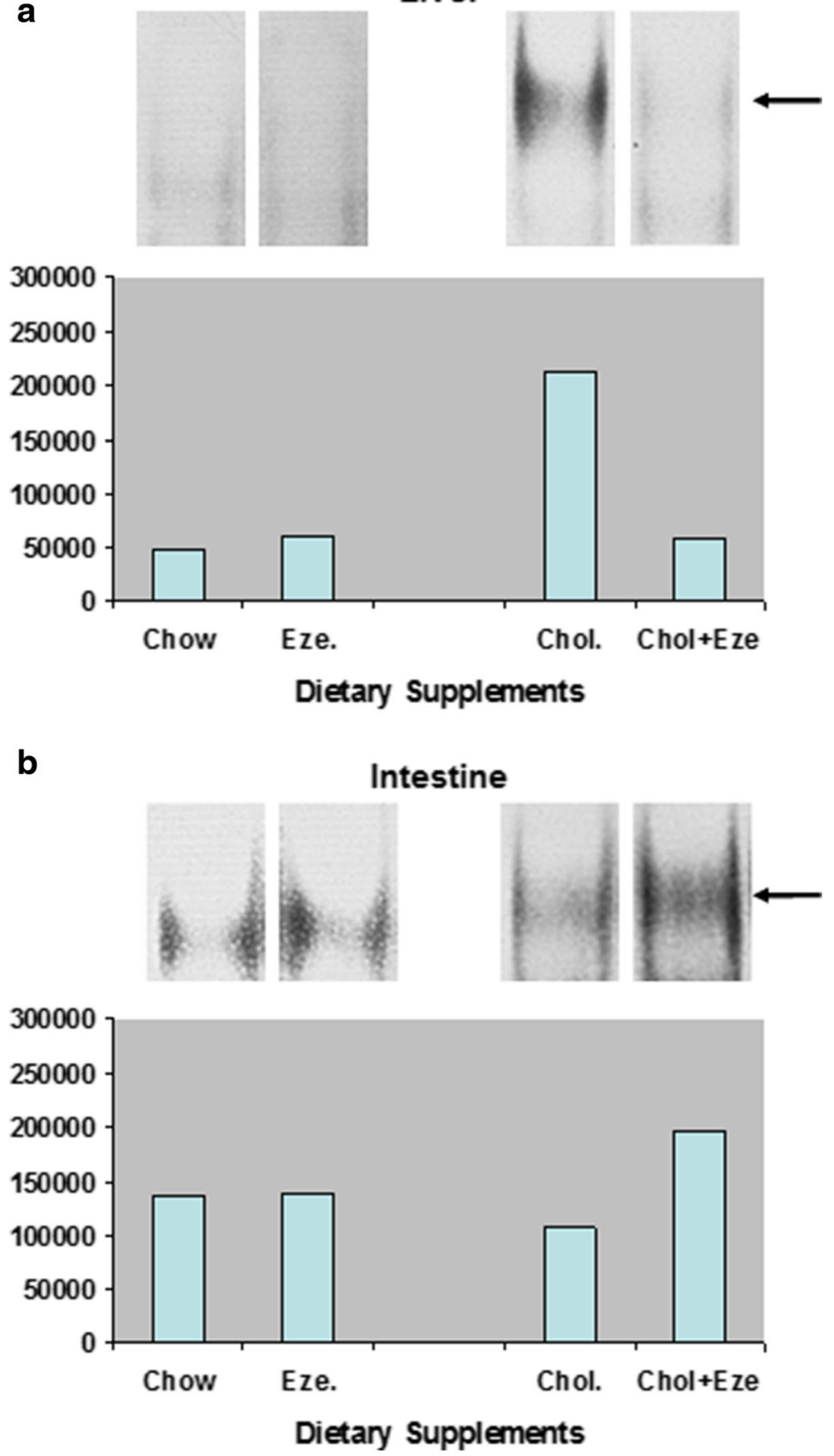

Fig. 3 Representative gelshift assays of NF-kappaB in nuclear extracts from liver (a) and intestine (b). Guinea pigs were maintained on the indicated diets for 2 weeks. Gel shift assays were performed on frozen liver and intestine tissue. Arrow denotes nuclear NF-kappaB band. Quantification of individual bands was done by ImageQuant software (ImageQuant ${ }^{\oplus}$, Molecular Dynamics, USA)

in animals on cholesterol rich diet in our study. However in animals receiving this diet in combination with ezetimibe this activation was prevented. In contrast to liver tissue, neutral fat accumulation as shown by oil red staining (see Fig. 2) and triglyceride content in intestinal tissue was further increased by ezetimibe (392\% versus $572 \%$ over control (see Table 5 ). Although triglycerides themselves are probably inert, their hydrolysis to free fatty acids and diacylglycerol may induce inflammatory response. It has been shown that these intracellular fatty acid 


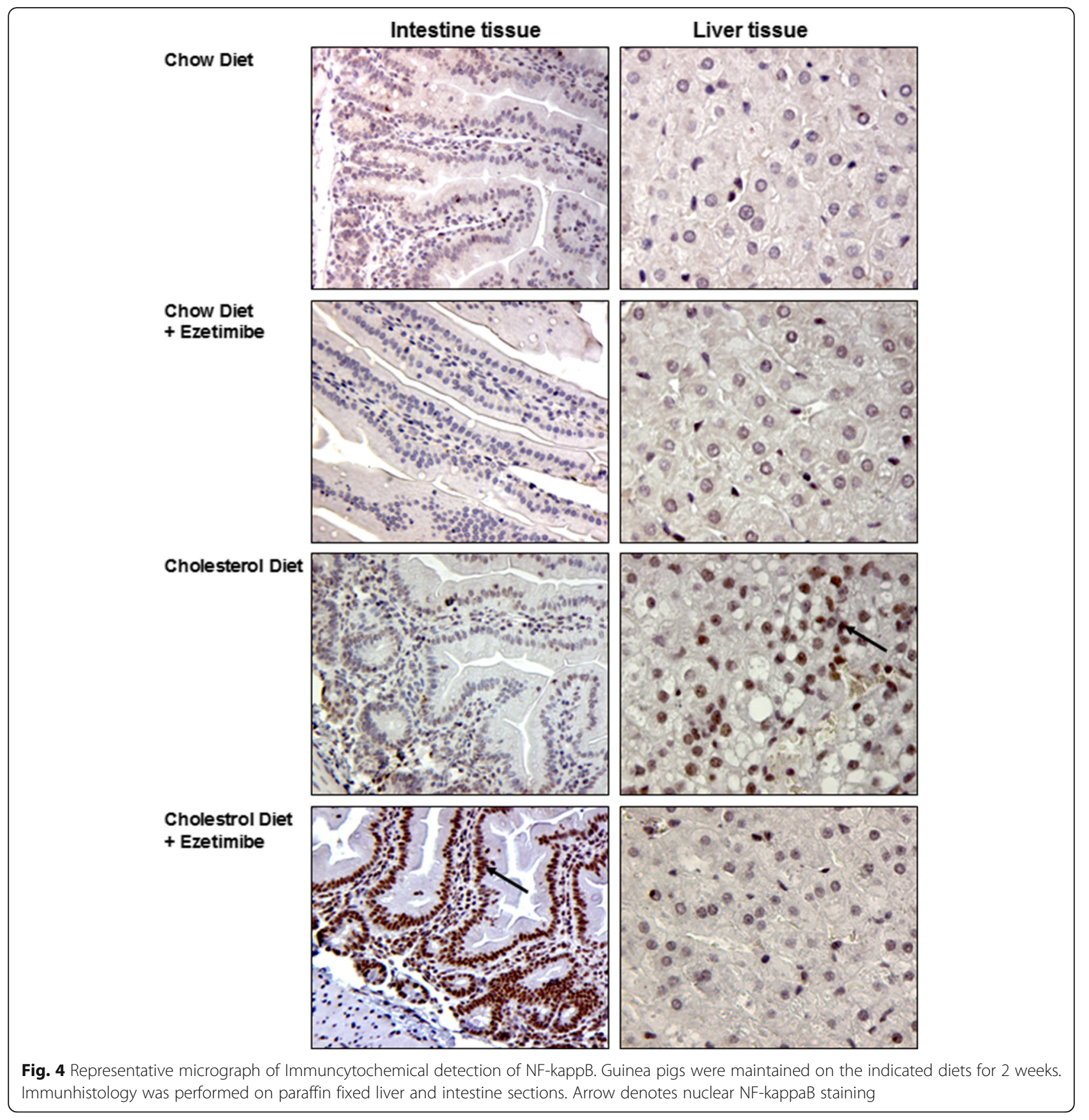

metabolites lead to endoplasmic reticulum (ER) stress and the activation of NF-kappa B signaling pathways [42, 43]. In our study ezetimibe treatment increase hepatic triglyceride content associated with a significant NF-kappaB activation. Whether this observation is a direct effect of ezetimibe or due to the triglyceride accumulation which may have inflammatory potential cannot be answered by this study.

\section{Conclusion}

The data presented in the present study lead us to conclude, that ezetimibe effectively reduced diet induced circulating cholesterol levels, hepatic lipid accumulation and inflammatory response in our guinea pig model. In contrast this drug elicited a local inflammatory response in intestinal tissue. Whether these diverse effects of ezetimibe on inflammatory parameters such as NF-kappaB have clinical relevance remains to be determined.

\section{Abbreviations}

ALT: Alanine transaminase; AST: Aspartate aminotransferase;

CHD: Coronary heart disease; EMSA: Electrophoretic mobility shift assay; gGT: Gamma-glutamyl transpeptidase; NAFLD: Non-alcoholic fatty liver disease 


\section{Acknowledgements}

Not applicable.

\section{Funding}

Not applicable.

\section{Availability of data and material}

The data are all presented in the main paper and supplementary material. All data used are in the laboratory books and are available to reviewers and all interested researchers.

\section{Authors' contribution}

$P F, E G, H J G, A K W$ performed the experiment. PF conceived and designed the study, drafted the manuscript. EG participated in the design of the study and coordination of the study. HJG participated in the design and coordination of the study and edited and revised the manuscript. HD participated in the design of the study, edited and revised the manuscript. AKW conceived and designed the study and edited and revised the manuscript. All authors read and approved the final manuscript.

\section{Competing interests}

The authors declare that they have no financial or non-financial competing interests for this manuscript

\section{Consent for publication}

Not applicable.

\section{Ethics approval and consent to participate}

All animal procedures were performed in accordance with the National Institutes of Health Guide for the Care and Use of Laboratory Animals and were approved by the Regierung von Oberbayern, Munich, Germany (Ref. Nb.: 209.1/211-2531.3-11/03).

\section{Author details}

${ }^{1}$ Medical Central Laboratories, Carinagasse 41, A-6800 Feldkirch, Austria. ${ }^{2}$ Department of Cellular and Molecular Pathology, German Cancer Research Center, Heidelberg, Germany. ${ }^{3}$ Vorarlberger Institute of Vascular Investigation and Treatment (VIVIT), Dornbirn, Austria. ${ }^{4}$ Institute of Laboratory Medicine, Ludwig-Maximilians-University, Munich, Germany.

\section{Received: 2 September 2016 Accepted: 4 January 2017}

\section{Published online: 02 February 2017}

\section{References}

1. Parra $J$, Reddy KR. Hepatotoxicity of hypolipidemic drugs. Clin Liver Dis. 2003:7:415-33.

2. Calderon RM, Cubeddu LX, Goldberg RB, Schiff ER. Statins in the treatment of dyslipidemia in the presence of elevated liver aminotransferase levels: a therapeutic dilemma. Mayo Clin Proc. 2010;85:349-56.

3. Goldberg AC, Sapre A, Liu J, Capece R, Mitchel YB. Ezetimibe Study Group. Efficacy and safety of ezetimibe coadministered with simvastatin in patients with primary hypercholesterolemia: a randomized, double-blind, placebocontrolled trial. Mayo Clin Proc. 2004;79:620-9.

4. Mikhailidis DP, Lawson RW, McCormick AL, Sibbring GC, Tershakovec AM, Davies GM, et al. Comparative efficacy of the addition of ezetimibe to statin vs. statin titration in patients with hypercholesterolaemia: systematic review and meta-analysis. Curr Med Res Opin. 2011;27:1191-210.

5. Enjoji M, Machida K, Kohjima M, Kato M, Kotoh K, Matsunaga K, et al. NPC1L1 inhibitor ezetimibe is a reliable therapeutic agent for non-obese patients with nonalcoholic fatty liver disease. Lipids Health Dis. 2010;9:29.

6. Ahmed MH, Byrne CD. Potential therapeutic uses for ezetimibe beyond lowering LDL-c to decrease cardiovascular events. Diabetes Obes Metab. 2011;12:958-66

7. Park H, Shima T, Yamaguchi K, Mitsuyoshi H, Minami M, Yasui K, et al. Efficacy of long-term ezetimibe therapy in patients with nonalcoholic fatty liver disease. J Gastroenterol. 2011:46:101-7.

8. Videla LA. Oxidative stress signaling underlying liver disease and hepatoprotective mechanisms. World J Hepatol. 2009;1:72-8.

9. Cusi K. Role of obesity and lipotoxicity in the development of nonalcoholic steatohepatitis: pathophysiology and clinical implications. Gastroenterology. 2012;142:711-25. e6.
10. Rector RS, Thyfault JP, Wei Y, Ibdah JA. Non-alcoholic fatty liver disease and the metabolic syndrome: an update. World J Gastroenterol. 2008;14:185-92.

11. van Heek M, Farley C, Compton DS, Hoos L, Davis HR. Ezetimibe selectively inhibits intestinal cholesterol absorption in rodents in the presence and absence of exocrine pancreatic function. Br J Pharmacol. 2001;134:409-17.

12. Bays HE, Neff D, Tomassini JE, Tershakovec AM. Ezetimibe: cholesterol lowering and beyond. Expert Rev Cardiovasc Ther. 2008;6:447-70.

13. Mangat R, Warnakula S, Wang $Y$, Russell JC, Uwiera R, Vine DF, et al. Model of intestinal chylomicron over-production and ezetimibe treatment: impact on the retention of cholesterol in arterial vessels. Atheroscler Suppl. 2010;11:17-24.

14. Temel RE, Tang W, Ma Y, Rudel LL, Willingham MC, loannou YA, et al. Hepatic Niemann-Pick C1-like 1 regulates biliary cholesterol concentration and is a target of ezetimibe. J Clin Invest. 2007;117:1968-78.

15. Assy N, Grozovski M, Bersudsky I, Szvalb S, Hussein O. Effect of insulin-sensitizing agents in combination with ezetimibe, and valsartan in rats with non-alcoholic fatty liver disease. World J Gastroenterol. 2006;12:4369-76.

16. Deushi M, Nomura M, Kawakami A, Haraguchi M, Ito M, Okazaki M, et al. Ezetimibe improves liver steatosis and insulin resistance in obese rat model of metabolic syndrome. FEBS Lett. 2007;581:5664-70.

17. Zheng S, Hoos L, Cook J, Tetzloff G, Davis Jr H, van Heek M, et al. Ezetimibe improves high fat and cholesterol diet-induced non-alcoholic fatty liver disease in mice. Eur J Pharmacol. 2008;584:118-24.

18. Phan BA, Dayspring TD, Toth PP. Ezetimibe therapy: mechanism of action and clinical update. Vasc Health Risk Manag. 2012;8:415-27.

19. Takemoto M, Liao JK. Pleiotropic effects of 3-hydroxy-3-methylglutaryl coenzyme a reductase inhibitors. Arterioscler Thromb Vasc Biol. 2001:21:1712-9.

20. Kuhlencordt PJ, Padmapriya P, Rützel S, Schödel J, Hu K, Schäfer A, et al. Ezetimibe potently reduces vascular inflammation and arteriosclerosis in eNOS-deficient ApoE ko mice. Atherosclerosis. 2009;202:48-57.

21. Qin L, Yang YB, Yang YX, Zhu N, Li SX, Liao DF, et al. Anti-Inflammatory Activity of Ezetimibe by Regulating NF-KB/MAPK Pathway in THP-1 Macrophages. Pharmacology. 2014;93:69-75

22. Berthold HK, Berneis K, Mantzoros CS, Krone W, Gouni-Berthold I. Effects of simvastatin and ezetimibe on interleukin-6 and high-sensitivity C-reactive protein. Scand Cardiovasc J Suppl. 2013:47:20-7.

23. Kalogirou M, Tsimihodimos V, Elisaf M. Pleiotropic effects of ezetimibe: do they really exist? Eur J Pharmacol. 2010;633:62-70.

24. Fernandez ML. Guinea pigs as models for cholesterol and lipoprotein metabolism. J Nutr. 2001;131:10-20.

25. Conde K, Pineda G, Newton RS, Fernandez ML. Hypocholesterolemic effects of 3-hydroxy-3-methylglutaryl coenzyme A (HMG-CoA) reductase inhibitors in the guinea pig: atorvastatin versus simvastatin. Biochem Pharmacol. 1999;58:1209-19.

26. Wollenberger A, Ristau O, Schoffa G. A simple technic for extremely rapid freezing of large pieces of tissue. Pflugers Arch Gesamte Physiol Menschen Tiere. 1960;270:399-412.

27. Fukuma K, Marubayashi S, Okada K, Yamada K, Kimura A, Dohi K. Effect of lazaroid U-74389G and methylprednisolone on endotoxin-induced shock in mice. Surgery. 1999:25:421-30.

28. Walli AK, Seidel D. Role of lipoprotein-X in the pathogenesis of cholestatic hypercholesterolemia. Uptake of lipoprotein- $X$ and its effect on 3- hydroxy-3-methylglutaryl coenzyme A reductase and chylomicron remnant removal in human fibroblasts, lymphocytes, and in the rat. J Clin Invest. 1984;74:867-79.

29. Kovanen PT, Brown MS, Goldstein JL. Increased binding of low density lipoproteins to liver membranes from rats treated with 17 alpha-ethinyl estradiol. J Biol Chem. 1979;254:11367-73.

30. Carr TP, Andresen CJ, Rudel LL. Enzymatic determination of triglyceride, free cholesterol, and total cholesterol in tissue lipid extracts. Clin Biochem. 1993:26:39-42.

31. Taylor AJ, Villines TC, Stanek EJ, Devine PJ, Griffen L, Miller M, et al. Extended-release niacin or ezetimibe and carotid intima-media thickness. N Engl J Med. 2009;361:2113-22.

32. Khanderia U, Regal RE, Rubenfire M, Boyden T. The ezetimibe controversy: implications for clinical practice. Ther Adv Cardiovasc Dis. 2011;5:199-208.

33. van Heek M, Compton DS, Davis HR. The cholesterol absorption inhibitor, ezetimibe, decreases diet-induced hypercholesterolemia in monkeys. Eur J Pharmacol. 2001:415:79-84.

34. Tremblay AJ, Lamarche B, Cohn JS, Hogue JC, Couture P. Effect of ezetimibe on the in vivo kinetics of apoB-48 and apoB-100 in men with primary hypercholesterolemia. Arterioscler Thromb Vasc Biol. 2006;26:1101-6. 
35. Sudhop T, Lütjohann D, Kodal A, Igel M, Tribble DL, Shah S, et al. Inhibition of intestinal cholesterol absorption by ezetimibe in humans. Circulation. 2002;106:1943-8.

36. Davidson MH, McGarry T, Bettis R, Melani L, Lipka LJ, LeBeaut AP, et al. Ezetimibe coadministered with simvastatin in patients with primary hypercholesterolemia. J Am Coll Cardiol. 2002;40:2125-34.

37. Ahmed MH, Byrne CD. Ezetimibe as a potential treatment for non-alcoholic fatty liver disease: is the intestine a modulator of hepatic insulin sensitivity and hepatic fat accumulation? Drug Discov Today. 2010;5:590-5.

38. Ribeiro PS, Cortez-Pinto H, Solá S, Castro RE, Ramalho RM, Baptista A, et al. Hepatocyte apoptosis, expression of death receptors, and activation of NF-kappaB in the liver of nonalcoholic and alcoholic steatohepatitis patients. Am J Gastroenterol. 2004;99:1708-17.

39. Cortez-Pinto H, de Moura MC, Day CP. Non-alcoholic steatohepatitis: from cell biology to clinical practice. J Hepatol. 2006:44:197-208.

40. Duvnjak M, Lerotić I, Barsić N, Tomasić V, Virović Jukić L, Velagić V. Pathogenesis and management issues for non-alcoholic fatty liver disease. World J Gastroenterol. 2007;13:4539-50.

41. Itani SI, Ruderman NB, Schmieder F, Boden G. Lipid-induced insulin resistance in human muscle is associated with changes in diacylglycerol, protein kinase C, and IkappaB-alpha. Diabetes. 2002;51:2005-11.

42. Eizirik DL, Cardozo AK, Cnop M. The role for endoplasmic reticulum stress in diabetes mellitus. Endocr Rev. 2008;29:42-61.

43. Tripathy D, Mohanty P, Dhindsa S, Syed T, Ghanim H, Aljada A, et al. Elevation of free fatty acids induces inflammation and impairs vascular reactivity in healthy subjects. Diabetes. 2003;52:2882-7.

\section{Submit your next manuscript to BioMed Central and we will help you at every step:}

- We accept pre-submission inquiries

- Our selector tool helps you to find the most relevant journal

- We provide round the clock customer support

- Convenient online submission

- Thorough peer review

- Inclusion in PubMed and all major indexing services

- Maximum visibility for your research

Submit your manuscript at www.biomedcentral.com/submit 